\title{
Regenerating cities with community-based inclusive waste management practices
}

\author{
J. Gutberlet \\ University of Victoria, Canada
}

\begin{abstract}
Solid waste $-\mathrm{a}$ visible result of growth oriented production and consumption - is a major urban challenge worldwide, with a myriad of impacts on the environment, public health and economy of local communities. There is increasing recognition that growth cannot be reconciled with the environment and that current economic and productive relations as well as identities need to be re-conceptualized away from 'capitalocentric' thinking. With the majority of the world's population living in cities, urban spaces also become centre stages for social movements and alternative economies, based on critiques of growth. Reclaiming and reintroducing recyclable materials into material flows, is one of the immediate responses of a radical politics of de-growth. Worldwide waste pickers organize and retrieve recyclable materials, for reuse and further industrial processing. These collectives re-imagine their production and economic activities in terms other than those made available by capitalism. Their everyday actions produce democratic spaces centred on solidarity and the care of others, and also seeking to reclaim citizenship. The collective practices of recycling cooperatives generate social, economic and environmental benefits, but are not yet widely perceived as such, nor are waste pickers generally remunerated fairly for the services they provide. In Brazil, the waste pickers movement is a notable grassroots example, where members enact new practices, linking up the local spaces and actions into a broader political movement, bringing political debates to a broader audience. The paper discusses the role of waste pickers as political actors, central to moving towards a reconceptualization of the economy in terms of de-growth and alternative development, through co-production in selective waste collection.
\end{abstract}

Keywords: solid waste, recycling, cooperative, waste pickers, co-production, community based research, political ecology. 


\section{Introduction}

Waste, as a direct outcome of human production and consumption processes, has become infinitely more complex and convoluted, heightening the uncertainties that threaten the planet. Our current waste regime is characterized by an exponential increase in volume and material diversification of discarded objects and substances, as a consequence of increases in packaging, shorter product durability, programmed obsolescence, economic growth logic, consumerism, and mass consumption. "Waste regimes consist of social institutions and conventions that not only determine what wastes are considered valuable but also regulate their production and distribution" (Gille [1, p. 29]) and, further, shape the decisions over what to do with our waste.

Consumption has changed in quality and quantity also in the global South, where cities have widely adopted the western waste regime, with a lack of appropriate measures (policies, educational or other strategies) to tackle the problem at its roots. If collected, the final destinations for household waste are still dumps and landfills. In informal settlements, waste is often not collected, posing human and environmental health hazards. Worldwide informal waste pickers organize in cooperatives, associations, unions or networks, focusing on the politics of selective waste collection, collective resale operations and material transformation. These groups challenge conventional decision-making processes, insisting on their participation in policy design and service provision related to waste management. "Policy making is no longer seen as a purely top-down process but rather as a negotiation among many interacting policy systems" (Bovaird [2, p. 846]). There are many examples where waste pickers themselves become city co-producers of waste collection and recycling services. They partner with local governments and perform selective waste collection.

Co-production helps understand the partnership arrangements in public service provision. The concept is defined as "the process through which inputs used to produce a good or service are contributed by individuals who are not "in" the same organization" (Ostrom [3, p. 1073]). Joshi and Moore [4] describe institutionalized co-production as the "provision of public services (broadly defined, to include regulation) through regular, long-term relationships between state agencies and organized groups of citizens, where both make substantial resource contributions" (p. 40).

This paper is based on participatory action research (PAR), conducted in the global South, applying inclusive methodology and epistemology, where knowledge is co-created and jointly validated by the research participants. Situated urban political ecology (UPE) (Heynen et al. [5]) provide the theoretical lens to the understanding of the social, economic, political and environmental conditions in the cities in the global South, to tease out community resilience and urban sustainability. 


\section{Situated UPE and solid waste co-production}

In most current capitalist societies economic growth is based on continuous consumption. A focus on solid waste clearly demonstrates that growth based economic development is unsustainable and urgently requires a paradigm shift. The UPE approach identifies actors and their agendas, and explores power relations within the given contexts. Cities are urban metabolisms where nature and society is interdependent and where processes and flows affect both spheres [5]. The solid waste system comprises the human (e.g. consumers, waste pickers, waste collectors, public administrators, recycling industry) and the non-human components (e.g. waste, infrastructure, groundwater, air, space) as well as specific processes (e.g. legislation, waste management techniques, community networks, human behavior) and interrelations (e.g. the way people are connected to waste).

Many of our current societal challenges (environmental degradation, climate change, poverty) can be linked to consumption and discard and can be addressed through politicising waste. Consumption and discard patterns (waste systems) are historically contextualized (waste regime) and waste management (the practical approach to waste) is shaped by dominant economy and politics. The stakeholders involved in waste management strive to create and defend their agendas, delineated by the realms of power that restrict or allow their reach.

Brazil's recycling cooperative movement is inscribed within the solidarity economy, characterized as community economy, emerging from the lens of difference and bringing to light marginalized and often hidden, heterodox economic activities (Gibson-Graham [6]). Sometimes these situations allow for co-production arrangements in public waste service provisions.

\section{Urban solid waste management in Brazil}

Most solid waste in Brazil is landfilled, however almost half of it is not disposed of properly. Despite the existence of a few formal recycling programs, the informal sector recovers most resources. The informal sector and micro-enterprise recycling, reuse, and repair systems achieve significant recycling rates, with 20 to $30 \%$ in low-income countries; an activity which saves local authorities around $20 \%$ or more in waste management costs. Worldwide, these informal activities provide a livelihood to approximately $1 \%$ of the urban population in the global South (Gutberlet [7]). There are currently approximately 30.390 waste pickers organized in 1,175 recycling cooperatives working in 648 municipalities in Brazil (IPEA [8]), many of which participate in the national waste pickers movement.

Over the past decade, organized waste pickers in Brazil have achieved greater visibility, better organization and improved working conditions. The national waste management law (Federal Law No. 12,305 of July 2010, regulated by Decree No. 7,404 of December 2010) holds opportunities for recycling cooperatives to establish partnerships with local governments for selective waste collection. Although waste pickers are actively supported and participate in policy development, o the everyday basis, however, the struggle continues, with most 
recyclers working informally, under precarious, unsafe conditions near the poverty line.

In Brazil the profession of waste picker (catador) is recognized since 2002. Several additional programs to fund recycling infrastructure in cooperatives and laws to support inclusive solid waste management and decent working conditions for informal recyclers (e.g. the federal program Pro-Catador) have been enacted since. The federal legislation also encourages municipalities to hire cooperatives for selective waste collection.

\section{Addressing urban resilience with inclusive waste management}

Urban resilience refers to the capacity of cities and their citizens to withstand and recover from disasters, including climate change, but also rapid over-urbanization and its negative social and environmental impacts. Resilience entails organizing change and recovery by an array of actors, often as a process that "for many people, will never quite end" (Vale and Campanella [9, p. 14]). In today's fast changing, complex and highly interconnected world, the focus on coping with change is central and thus has been applied to scholarship in many different fields, including waste management. Retrieving waste from the environment and recovering recyclable resources from households and local business, educating the population for more effective source separation are strategies that make cities more resilient, e.g. as environmental stewards applying transformative literacy during door-todoor collection (Schneidewind [10]). Collectively they have the ability to expand the public sector and transform the public sphere towards more sustainable consumption and discard processes.

The city Ribeirao Preto (666,323 inhabitants) in the state of São Paulo, e.g. has formalized co-production in waste management with the Cooperativa Mãos Dadas being in charge of selective waste collection, separation and commercialization (anchored in the municipal law 11.221/May 2007). Since 2008 the following actions have improved the working conditions in the cooperative and waste management in the city: (a) increased selective waste collection coverage; (b) environmental education; (c) better occupational health of waste pickers, (d) acquisition of proper equipment and infrastructure; (e) establishment of 5 new recycling depots in the city; (f) fourfold income increase for waste pickers. The co-production format applied in this city contributes to improved environmental education, reflecting in better source separation quality and reduced material rejection rates (currently between 5 and $10 \%$ of the material that enters the depot).

In contrast, the city of São Paulo (12 million inhabitants) has contracted two corporations (LOGA and ECOURBIS) for the collection of waste and recyclables. In addition, since 2014, the city has established 3 forms of contracts with: (1) recognized, formalized cooperatives to do selective waste collection in city sub-regions; (2) cooperatives to service the currently two mechanized large scale recycling centers; (3) cooperatives which are not yet formalized but already engage in selective waste collection in parts of the city. ECOURBIS collects 
recyclable household waste in the southeast of São Paulo and transports it to the recycling center Megacentral-Sul. Here, 65 of the total 127 members of the cooperative Coopercaps work in the mechanized material separation. ECOURBIS does not carry out environmental education, resulting in inefficient source separation. The compactor trucks used in the collection of mixed household recyclables, makes the posterior separation hazardous; resulting in a rejection rate of $48 \%$ of all material that enters the recycling plant. Today this plant processes 125 tons/day. It does not process glass (which accounts for $19 \%$ of the rejected material). Nevertheless, the city's heavy investment in recycling infrastructure has contributed to an increase of the official recycling rate from $1 \%$ to $3.6 \%$ in 2016 .

A 3rd example demonstrates how groups organized in networks have obtained heightened negotiating power and are potentially more successful in co-managing waste. Recycling cooperatives in 19 municipalities in northeastern metropolitan São Paulo have organized into the network Rede Solidaria CataVida. They practice collective commercialization and have accessed specific government funding for capacity building and infrastructure expansion. This has allowed them to set up an industry in Sorocaba city, to transform plastics (PP and PEAD), collected by these cooperatives, into pellets. This operation has increased the material value for plastic almost four times, raising the cooperative members' average income above the formal minimum salary. The network also provides support in negotiations between the cooperatives and the local governments.

\section{Conclusion}

In a transition away from wastefulness towards resource recovery, the proposed waste management co-production involving organized waste pickers helps tackle the objectives of a "low-carbon, resource efficient, resilient and socially inclusive economy" (Zaman and Lehmann [11]). Diverse examples of cooperative recycling evidence opportunities for redesigning cities into more sustainable, resilient places. It is an opportunity to expand the scope of these initiatives for more significant impacts, maximizing recovery rates, and increasing the waste awareness level of governments, industry, and the public at large.

Most successful are those cases with formalized co-production, where local governments remunerate cooperatives or networks to perform door-to-door collection, separation and commercialization of recyclables. Public policies for participatory approaches in waste management are crucial to guarantee the success of these programs. Legislation has the potential to safeguard on-going support beyond party politics. Technology needs to be appropriate to avoid material contamination or destruction (as do compactor trucks) and it needs to be socially appropriate, generating inclusive employment (as door-to-door household waste collection does).

Cities can save energy and decrease their greenhouse gas footprint with recycling (King and Gutberlet [12]). Cities can reduce the pressure on natural resources by intensifying reduction, reuse and recycling. Trans-disciplinary research, inter-sectorial policy approaches, and participatory praxis come into play, when creating awareness about waste disposal and waste reduction; and 
when creating municipal, provincial/state and national/international regulations for avoidance, reduction, reuse and recycling. Such integrated approaches inform industry in creating viable products.

Redesigning cities means collectively shifting away from a regime of waste accumulation, molded by practices that exploit labor and the environment, towards new sets of social, economic and institutional arrangements, expanding and valuing the multiple potential services that can be provided by waste pickers. Inclusive waste management brings low barrier jobs, which are particularly important in the global South and in transition economies. This logic implies changing infrastructures, technologies, policies, and cultures towards waste prevention, reduction, reuse, recycling and extended producer responsibility for every product. Re-using, repairing and recycling are also good for the local economy. The paper has discussed different challenges and benefits of inclusive waste management in Brazil. Waste co-production requires supportive local governments, willing to remunerate the service of selective waste collection. With resilience being mostly a function of resourceful citizens, organized waste pickers can play an important role in engaging and educating citizens in source separation and responsible consumption/discard.

\section{References}

[1] Gille, Z., From risk to waste: global food waste regimes. The Sociological Review, 60(S2), pp. 27-46, 2013.

[2] Bovaird, T. Beyond Engagement and Participation: User and Community Coproduction of Public Service. Public Administration Review, 67(5), pp. 846-860, 2007.

[3] Ostrom, E., Crossing the Great Divide: Coproduction, Synergy, and Development. World Dev., 24(6), pp. 1073-1087, 1996.

[4] Joshi, A. \& Moore, N., Institutionalised Co-Production: Unorthodox Public Service Delivery in Challenging Environments. The Journal of Development Studies, 40(4), pp. 31-49, 2004.

[5] Heynen, N., Kaika, M. \& Swyngedouw E. Urban political ecology: politicizing the production of urban natures, in: In The Nature of Cities: Urban Political Ecology and the Politics of Urban Metabolism. N. Heynen, M. Kaika, and E. Swyngedouw (Eds) London: Routledge, pp. 1-20, 2006.

[6] Gibson-Graham, J.K., A Postcapitalist Politics, University of Minnesota Press, Minneapolis, MN, 2006.

[7] Gutberlet, J., Urban Recycling Cooperatives. Building resilient communities, Routledge, New York, 2016.

[8] IPEA (Instituto de Pesquisa Econômica Aplicada). Pesquisa sobre pagamento por serviços ambientais urbanos para gestão de resíduos sólidos, Diretoria de Estudos e Políticas Regionais Urbanos e Ambientais (DIRUR), Brasília, 2011.

[9] Vale, L.J. \& Campanella, T.J., The Resilient City. How Modern Cities Recover from Disaster, Oxford University Press, NY, 2005. 
[10] Schneidewind, U., Transformative Literacy: Gesellschaftliche Veränderungsprozesse verstehen und gestalten. GAIA 22(2), pp. 82-86, 2013.

[11] Zaman, A.U. \& Lehmann, S., Urban growth and waste management optimization towards 'zero waste city'. City, Culture and Society, 2(4), pp. 177-187, 2011.

[12] King, M. \& Gutberlet, J., Contribution of cooperative sector recycling to greenhouse gas emissions reduction: a case study of Ribeirão Pires, Brazil. Waste Management, 33(12), pp. 2771-2780, 2013. 